\title{
PERCEPÇÃO DOS FUNCIONÁRIOS DE UMA EMPRESA DE SANEAMENTO BÁSICO SOBRE A IMPLANTAÇÃO DA ISO 9000
}

OLIMPIO, Eliseu Marzagão ${ }^{1}$

PENEDO, Antônio Sérgio Torres Penedo ${ }^{2}$

RESUMO: A ISO 9000 é um conjunto de normas e diretrizes para o gerenciamento da qualidade. A partir do momento que uma empresa decide adotá-la ocorre uma série de mudanças em toda sua estrutura. Este artigo tem por objetivo apresentar um estudo sobre o conhecimento e o envolvimento dos funcionários de uma empresa de saneamento básico sobre o programa ISO 9000 implantado. Para tanto, foi elaborado um questionário com dez perguntas fechadas e aplicado junto aos funcionários de uma empresa de saneamento básico da região de Ituverava, localizada no interior do estado de São Paulo. Analisando os resultados obtidos, observa-se que grande parte dos funcionários têm conhecimento do ISO programa e dos benefícios que proporcionaram sua implantação.

Palavras chave: Gestão da Qualidade. Ambiente de trabalho. Organização empresarial.

\section{PERCEPTION OF THE ONE EMPLOYEES COMPANY OF BASIC SANITATION ON THE IMPLANTATION OF ISO 9000}

SUMMARY: ISO 9000 is a set of norms and lines of direction for the management of the quality, from the moment that a company decides to adopt it occurs a series of changes in all its structure. This article has for objective to present a study on the knowledge and the envolvement of the employees of the company on implanted program ISO 9000 in the same one, for in such a way was elaborated a questionnaire with ten closed and applied questions next to the employees of a company of basic sanitation region of Ituverava, located in the interior of the São Paulo state. Analyzing the gotten results it is observed that great part of the employees has knowledge of the ISO programs and the benefits that had provided its implantation.

Keywords: Quality Management. Work environment. Organization.

\section{INTRODUÇÃO}

A série de normas ISO 9000 é um conjunto de normas e diretrizes internacionais para sistemas de gestão de qualidade. Desde sua primeira publicação, em 1987, ela tem obtido reputação mundial como base para o estabelecimento de sistema de gestão da qualidade. A vasta maioria das normas ISO é altamente específica para um produto, material ou processo

\footnotetext{
${ }^{1}$ Bacharel em Administração de Empresas Habilitação em Gestão de Negócios pela Faculdade de Filosofia Ciências e Letras de Ituverava - SP

${ }^{2}$ Prof. Dr. Em Engenharia de Produção. Fundação Educacional de Ituverava-FFCL/FAFRAM. FAO -Faculdade de Orlândia; Centro Universitário Claretiano de Batatais - CEUCLAR.
} 
particular. Contudo, tanto a norma ISO 9000 quanto a norma ISO 14000 são conhecidas como normas genéricas de sistemas de gestão (MELLO et al., 2007).

A qualidade que estava no início associada ao produto está se tornando cada vez mais abrangente com a generalização do fornecimento de serviços e o aumento da capacidade da oferta e também da concorrência por praticamente todos os seguimentos industriais. A qualidade pode ser definida como forma de estar, de conviver e de atuar, uma vez que a procura por melhores resultados hoje faz parte do processo produtivo em qualquer setor ou seguimento. Uma vez que a empresa dependa da clientela toda qualidade deve ser voltada para ela, no sentido de atendê-la cada vez melhor. Porém, a empresa não deve esquecer-se de seus clientes internos, procurando inseri-los no contexto da qualidade e procurando meios para que estes sintam motivados e profissionalmente realizados (DELGADO, 1996).

Por este motivo as organizações sofrem constantes transformações e adaptações às novas tecnologias, novos produtos e serviços, onde incluem técnicas e ferramentas de gestão em busca de um ambiente de qualidade (CHIAVENATO, 2002).

ISO (International Organization for Standardization), com sede em Genebra na Suíça é responsável por cuidar e elaborar mundialmente normas nos mais diferentes segmentos e especificações de produtos, matérias-primas, em todas as áreas. A ISO se popularizou a partir dos Sistemas para Gestão e Garantia da Qualidade, conhecido pela série 9000 (SGQ, 2009).

As normas ISO se relacionam aos processos, cujo conceito básico prevê uma nova forma de estruturar e gerenciar as atividades e as expectativas das organizações, de forma sistemática e integrada, alinhando os clientes à eficácia da organização como um todo. A homologação das Normas Brasileiras de Regulamentação - NBR ISO 9001, direcionada aos sistemas de gestão da qualidade em dezembro de 2000, trouxe muitas novidades em relação aos conceitos e fundamentos da gestão da qualidade (VALLS, 2004).

A idéia principal da ISO 9000 é estabelecer normas e critérios que visam um adequado gerenciamento do negócio tendo como foco principal a satisfação do cliente e consumidor, por meio de uma série de ações entre as quais podemos destacar, segundo SGQ (2009):

a) comprometimento com a qualidade em todos os níveis hierárquicos, desde os diretores até os operadores;

b) manter uma gestão de eficiência dos recursos humanos e materiais necessários para as operações do negócio;

c) procedimentos, instruções e registros de trabalho formalizando todas as atividades ;

d) monitoramento dos processos por meio de indicadores de eficiência;

e) tomada de ações quando os objetivos pré-estabelecidos não são alcançados 
$\mathrm{O}$ aspecto mais marcante da ISO está relacionado aos processos, pois este conceito prevê uma nova forma de estrutura e gerenciamento das organizações, sistematicamente alinhado aos interesses do cliente e das organizações, buscando a eficácia para ambos.

A implantação deste sistema é influenciada por várias necessidades e têm objetivos específicos como produtos fornecidos, processos empregados, tamanho e estrutura da organização. Segundo Campos (1994) e Marshall Júnior et al. (2006), qualidade é um sinônimo de sobrevivência para as empresas que disputam seu espaço num mundo de grandes avanços tecnológicos.

Cada vez mais é reconhecido que a melhoria na qualidade dos produtos e serviços é uma questão extremamente necessária para a competitividade das organizações. E produzir com qualidade, significa maior satisfação do cliente, especialização e alcance de mercado, elevação da competitividade e do lucro. Para o cliente, qualidade é um fator decisivo nas relações de consumo. Como o sucesso de uma organização depende cada vez mais do conhecimento, das habilidades e motivação de seus empregados, e o sucesso destes depende cada vez mais de oportunidades de aprendizagem e prática de novas habilidades, o presente trabalho analisou a percepção dos funcionários da empresa sobre a ISO 9000.

Dessa forma, o objetivo geral deste trabalho é investigar a percepção dos funcionários da empresa sobre as mudanças no setor produtivo, após a implantação da ISO 9000. Para complementar este objetivo são apresentados os seguintes objetivos específicos:

- avaliar o conhecimento dos colaboradores sobre o programa;

- avaliar a satisfação dos colaboradores com o programa;

- investigar o processo de implantação

O problema de pesquisa desse trabalho foi:

- avaliar qual a satisfação dos funcionários com a implantação do programa.

\section{REVISÃO DE LITERATURA}

Com a evolução a qualidade ao longo do século XX, quatro estágios surgiram para a inspeção do produto, sendo eles: a inspeção do produto, o controle do processo, os sistemas de garantia da qualidade e a gestão da qualidade total. A gestão da qualidade total (TQM Total Quality Management) e os sistemas de gestão da qualidade da série ISO 9000 são resultados importantes dessa evolução, usados por inúmeras organizações no Brasil e exterior, como parte da estratégia das empresas para ganho ou aumento da competitividade. A qualidade hoje significa satisfação do cliente quanto a adequação do produto ao uso, com essa definição, percebe-se que ha várias características que conferem qualidade ao produto sendo 
as principais: desempenho técnico ou funcional, disponibilidade, confiabilidade, mantenabilidade, durabilidade, conformidade, instalação e orientação de uso, assistência técnica, interface com o usuário, interface com o meio ambiente, estética, qualidade percebida e imagem da marca (CARPINETTI et al., 2007).

Pode-se estabelecer os objetivos da qualidade com base em dados históricos (volume de sucatas, quantidade de retrabalhos, número de pessoas etc.), estudos de engenharia (através da coleta de dados e análise científica dos mesmos estabelecendo limites de tolerância), ou mercado (buscando informações sobre os produtos ou serviços concorrentes). A norma ISO 9000:2000 recomenda avaliação da eficiência e eficácia dos processos por meio de análises críticas interna e externas e avaliadas por uma escala de maturidade. Os resultados são documentados e monitorados ao longo do tempo para atingir metas de melhoria, existem diversas tabelas de maturidade para os mais variados tipos de aplicação intitulados diretrizes para auto avaliação. Manutenção e melhoria continua, podem ser atingidas aplicando o conceito do ciclo $\mathrm{PDCA}^{3}$ em todos os níveis da organização, tanto para os processos estratégicos de alto nível como para o planejamento e a análise crítica do sistema de gestão da qualidade também para as operacionais executadas em partes dos processos de fabricação dos produtos (MELLO et al., 2007).

Segundo Bonfim (2006), na era da qualidade, a mudança organizacional não pode ser apenas uma alteração física, tecnológica ou comportamental. As mudanças precisam ocorrer em todos os níveis da organização em todos os processos, sendo integrada, partindo da estratégia e mudando a atitude de todos os indivíduos da organização. As grandes mudanças ocorridas no século XX influenciaram e transformaram as organizações e seus comportamentos. Podemos destacar que uma das mudanças foi o enfoque na qualidade que hoje é uma preocupação constante nas organizações. Parâmetros novos são incorporados gradativamente e transformam as estratégias para obtenção da qualidade em todos seus conceitos. Como o consumidor não aceita mais produtos de baixa qualidade, nos últimos anos os padrões de qualidade cresceram drasticamente. Em todas as organizações, é do conhecimento de todos que a qualidade representa a mais importante arma competitiva, sendo de suma importância para sua sobrevivência. A garantia da qualidade começa com a qualidade dos processos organizacionais buscando otimizar os recursos aplicados em todas as etapas da produção de um bem ou serviço prestado.

Além de ser fator determinante para aceitação pelo usuário ela é exigida para a certificação e validação, o selo ou qualquer outra forma de demonstração de existência de

\footnotetext{
${ }^{3} \mathrm{O}$ ciclo PDCA é um método gerencial para promover a melhoria continua: $\mathrm{P}$ planejamento, D execução do planejamento, $\mathrm{C}$ checar verificando se planejamento esta sendo alcançado, A agir corretivamente.
} 
qualidade nas empresas, o que torna fundamental para fazer diferença no mercado em que estão inseridas (BONFIM, 2006).

Chiavenato (1999) aborda diversas definições de qualidade de diferentes autores, conforme destacado:

- qualidade é a capacidade de atender, durante todo o tempo, as necessidades do cliente;

- qualidade é uma adequação à finalidade ou uso;

- qualidade é a conformidade das exigências;

- qualidade tem como objetivo as necessidades do usuário, presentes e futuras;

- qualidade é o total das características de um produto ou serviço referentes a marketing, engenharia, manufatura e manutenção, pelas quais o produto ou serviço, quando em uso, atenderá as expectativas do cliente;

- qualidade é a totalidade dos aspectos e características de um produto ou serviço, importantes para que ele possa satisfazer às necessidades exigidas ou implícitas.

Existindo ainda a diferença entre qualidade interna e externa, sendo que a qualidade interna é a forma como a organização administra seus processos, produtos e serviços, e a qualidade externa que se trata da percepção que o cliente, consumidor ou usuário tem a respeito do produto ou serviço que compra e utiliza (BONFIM, 2006 apud CHIAVENATO, 1999).

De acordo com Bergamo Filho (1999) a empresa que propõe a implantar a NBR ISO 9000 altera também seu sistema social e pode criar resistência naqueles que serão afetados, pois essas mudanças atingem pessoas e departamentos, que por sua vez poderão reagir contra as mudanças ou contra os responsáveis por elas. Ocorrem estas resistências quando:

- a alteração não está clara para indivíduos e áreas afetadas por ela;

- pessoas diferentes interpretam de maneira diferente uma mesma alteração;

- as pessoas são forçadas a aceitarem a alteração;

- a mudança é feita como um caráter pessoal sem envolvimento de todos;

- as pessoas não percebem fatos que comprovem a necessidade de mudança.

O termo mudança é muito forte e pode estimular idealismo, revolução e descontentamento, devemos trocá-lo pelo termo educação, que ao contrário significa uma alteração para o bem. Como educar é um modo de comunicar conhecimentos e/ou fornecer habilidades, a sugestão é que a ISO 9000 seja um instrumento de mudança, mas através da educação, principalmente no início de sua implantação (BERGAMO FILHO, 1999).

A empresa pode ter um controle rígido de seus funcionários, determinar normas 
severas, supervisionar, fiscalizar. Porém, nada é tão eficiente como o espírito de colaboração e a iniciativa daqueles que acreditam no que faz. A matéria prima mais importante de uma organização são as pessoas, por consequência o total envolvimento delas permite o melhor aproveitamento desse recurso e dos demais em favor da organização. Sempre deve estar atento para o fato de que as pessoas procuram além de uma remuneração adequada mais espaço e oportunidades para demonstrar aptidões, espírito participativo e vontade de crescer profissionalmente vendo seus esforços ser reconhecidos. Satisfazer tais objetivos é multiplicar o potencial de iniciativa e trabalho. Mas para haver o envolvimento e o comprometimento das pessoas da organização é necessária a sinalização da liderança da empresa sobre a importância do comprometimento com a qualidade, o foco no cliente e a melhoria continua de todos os processos. Esse papel é fundamental na alta administração fortalecendo esses princípios de gestão (CARPINETTI et. al., 2007).

As empresas que adotam a ISO 9000 têm grandes chances de sobrevivência no mercado competitivo, pois trata-se da melhor maneira de administrar seus processos. A ISO 9000 se resume em um conjunto de normas que inclui o acompanhamento continuo por meio de medições de todas as etapas de produção, não se esquecendo das pessoas, ou seja, do capital humano.

\section{METODOLOGIA}

Este estudo foi realizado em uma empresa de saneamento básico da região de Ituverava, localizado a noroeste do estado de São Paulo, no decorrer dos meses de abril a junho de 2010, que tem o programa da qualidade implantado.

Foi feito levantamento exploratório por meio de questionário estruturado, elaborado a partir de Oliveira (2007), com perguntas fechadas, junto aos funcionários, com o objetivo de obter informações sobre o grau de escolaridade, conhecimento sobre o programa de qualidade da empresa e as dificuldades e benefícios da implantação da ISO.

Os dados apurados neste questionário foram tabulados, analisados e utilizando estatística descritiva e apresentados os resultados em forma de gráfico.

De acordo com Yin (2005), um projeto de pesquisa constitui a lógica que unem dados a serem coletados (e conclusões a serem tiradas) às questões iniciais de um estudo. Cada estudo empírico possui um projeto de pesquisa implícito, se não explicito. Articular a "teoria" sobre o que está sendo estudado ajuda a operacionalizar os projetos de estudo de caso e a deixá-los mais explícitos. Além disso, o desenvolvimento de projetos de estudo de caso precisa maximizar quatro condições relacionadas à qualidade do projeto: 
a) validade do constructo (aquilo que é elaborado ou sintetizado com base em dados simples, esp. um conceito)

b) validade interna (apenas para estudos causais ou exploratórios);

c) validade externa;

d) confiabilidade.

Dessa maneira, procurando utilizar-se de meios rigorosos para o procedimento de estudo de caso, usou os critérios citados (YIN, 2005).

\section{RESULTADOS E DISCUSSÃO}

Os resultados obtidos no estudo da pesquisa de percepção dos funcionários sobre a implantação da ISO 9000 na empresa estudada são apresentados em gráficos e tabelas, de acordo com os dados mais relevantes da pesquisa.

Tabela 1 - Formação Profissional.

\begin{tabular}{lcc}
\hline \multicolumn{1}{c}{ Formação Profissional } & Frequência absoluta & Frequência relativa (\%) \\
\hline Técnico & 39 & 55,71 \\
\hline Agente de Saneamento & 12 & 17,14 \\
\hline Engenheiro & 05 & 7,13 \\
\hline Operador de Equipamentos & 03 & 4,29 \\
\hline Atendentes & 02 & 2,86 \\
\hline Gerentes & 02 & 2,86 \\
\hline Encarregados & 02 & 2,86 \\
\hline Desenhista & 01 & 1,43 \\
\hline Eletricista & 01 & 1,43 \\
\hline Agente de Manutenção & 01 & 1,43 \\
\hline Analista de Gestão & 02 & 2,86 \\
\hline Total & 70 & 100,00
\end{tabular}

Dos 76 questionários levantados na empresa, apenas 06 funcionários não quiseram responder aos dados perguntados, conforme tabela acima, limitando-se apenas a responderem sobre o tempo de trabalho na empresa.

Com relação ao tempo de trabalho na empresa, nota-se que a maioria dos funcionários trabalham há mais de 5 anos na empresa. 


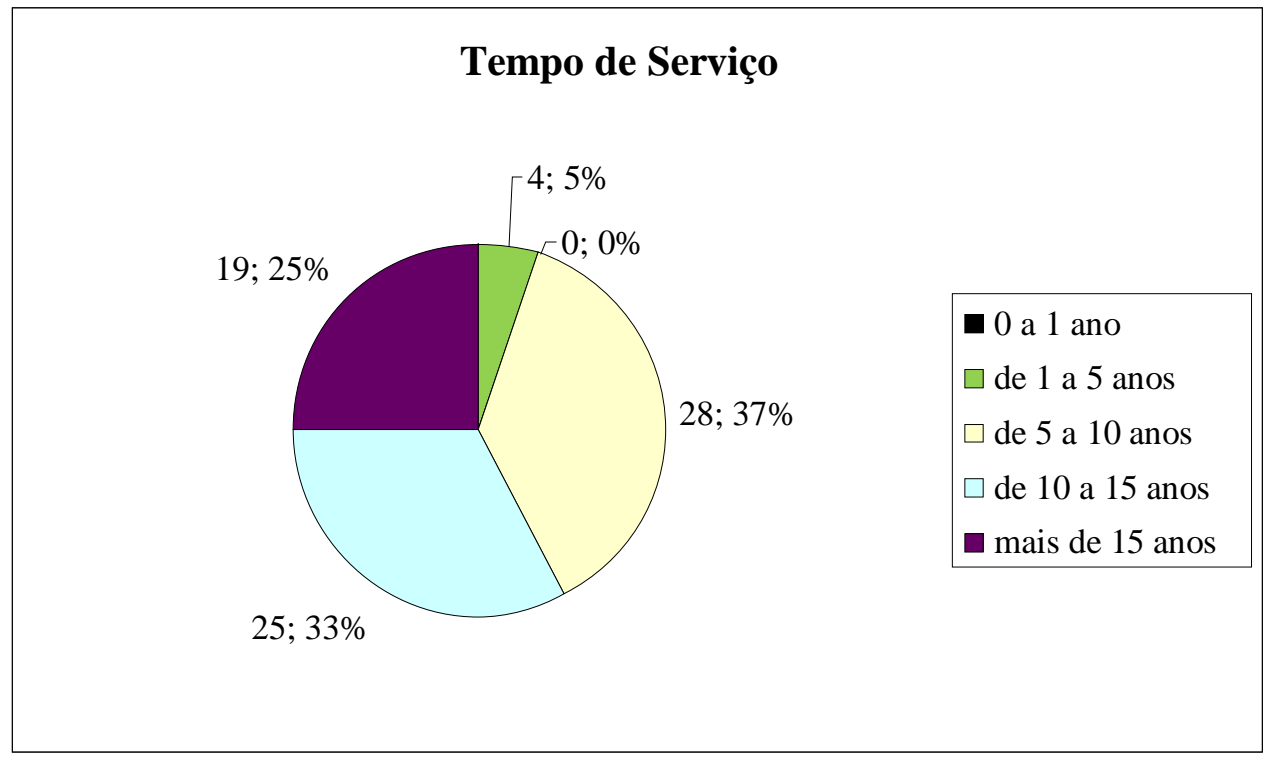

Figura 1 - Tempo de serviço.

Perguntados sobre o ano de implantação do ISO 9000 na empresa em que trabalham, de todos os pesquisados (76), houveram (58) respostas "Sim" e (18) respostas "Não", sendo que das 58 respostas "Sim", 28 indicaram corretamente o ano de 2002, enquanto 27 se equivocaram na data da implantação, e os outros (03) restantes "deixaram a pergunta sem responder'.

\section{Conhecimento sobre o ISO 9000 e participação em algum programa de treinamento na sua empresa}

Do total de funcionários pesquisados (76) constatou-se que: 59 apresentam conhecimento, 14 afirmaram conhecer pouco, 1 afirmou saber muito pouco sobre o programa, enquanto 2 declararam não conhecer.

Quanto à participação em algum treinamento sobre o ISO 9000, cerca de 84,21\% do total de pesquisados responderam que "sim" perfazendo 64 funcionários, enquanto 12 $(15,79 \%)$ afirmaram “não".

Informa-se que os resultados obtidos sobre a pergunta "Conscientização sobre a execução de tarefas após a implantação com o ISO 9000" houveram 66 respostas "Sim", 9 respostas "Não" e apenas 01 deixou a pergunta sem responder. Evidencia-se assim que, do total de funcionários pesquisados, podemos concluir que $86,84 \%$ deles são conscientes sobre a importância de executarem suas tarefas em conformidade com o ISO 9000.

Os resultados obtidos pertinentes à pergunta sobre os benefícios observados pelos 
funcionários pesquisados na empresa com a implantação do ISO 9000 estão relacionados no gráfico abaixo:

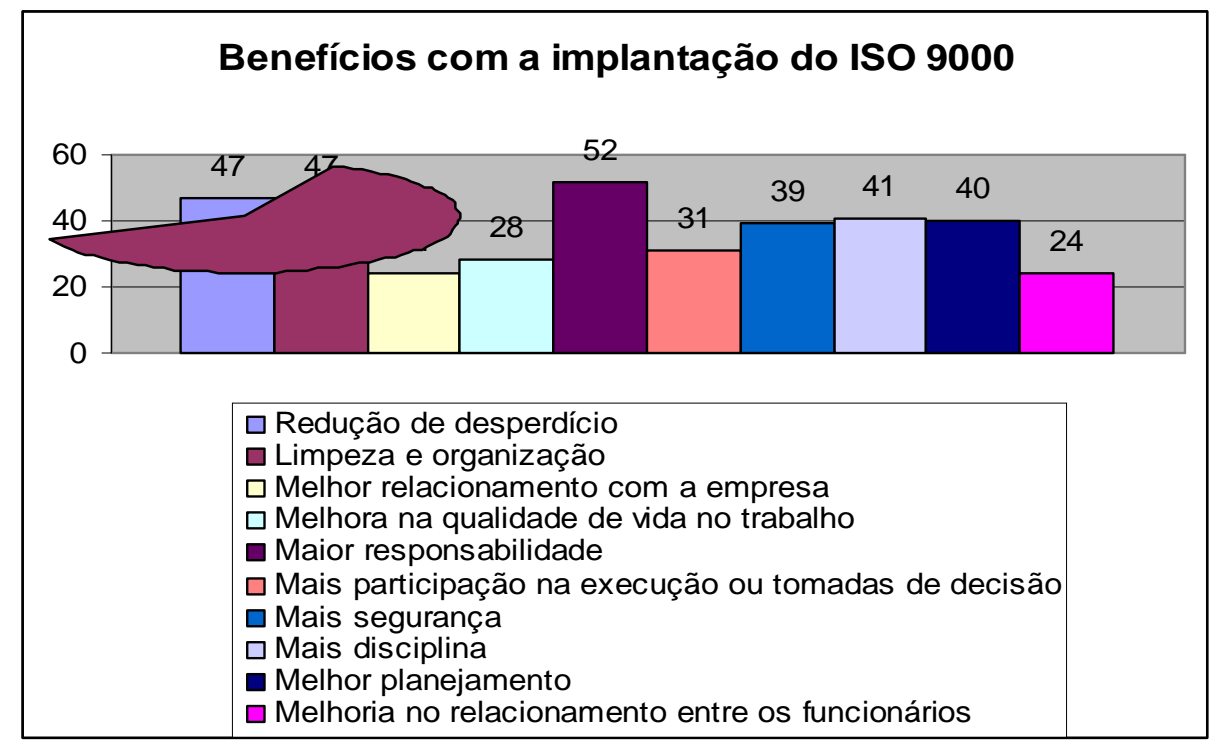

Figura 2 - Benefícios com a implantação do ISSO 9000.

Quanto às dificuldades encontradas pelos funcionários para se adaptarem ao programa do ISO 9000, a maioria (56) correspondentes a 73,68\% do total afirmaram não enfrentarem maiores problemas de adaptação, enquanto 17 funcionários $(22,36 \%)$ do total declararam que sentiram dificuldades de adaptação com a implantação do programa em questão. Nesta questão levantada, 02 funcionários deixaram de responder por questões pessoais.

Do total de pesquisados (76), a maioria (48) atestam "Sim" às possibilidades fornecidas pela empresa para que estes possam sugerir melhorias no desempenho e funcionamento do programa do ISO 9000, outros 23 atestam "Não" para sugestões ou espaço para opiniões. Neste item, 5 funcionários se reservaram ao direito de não responderem. 


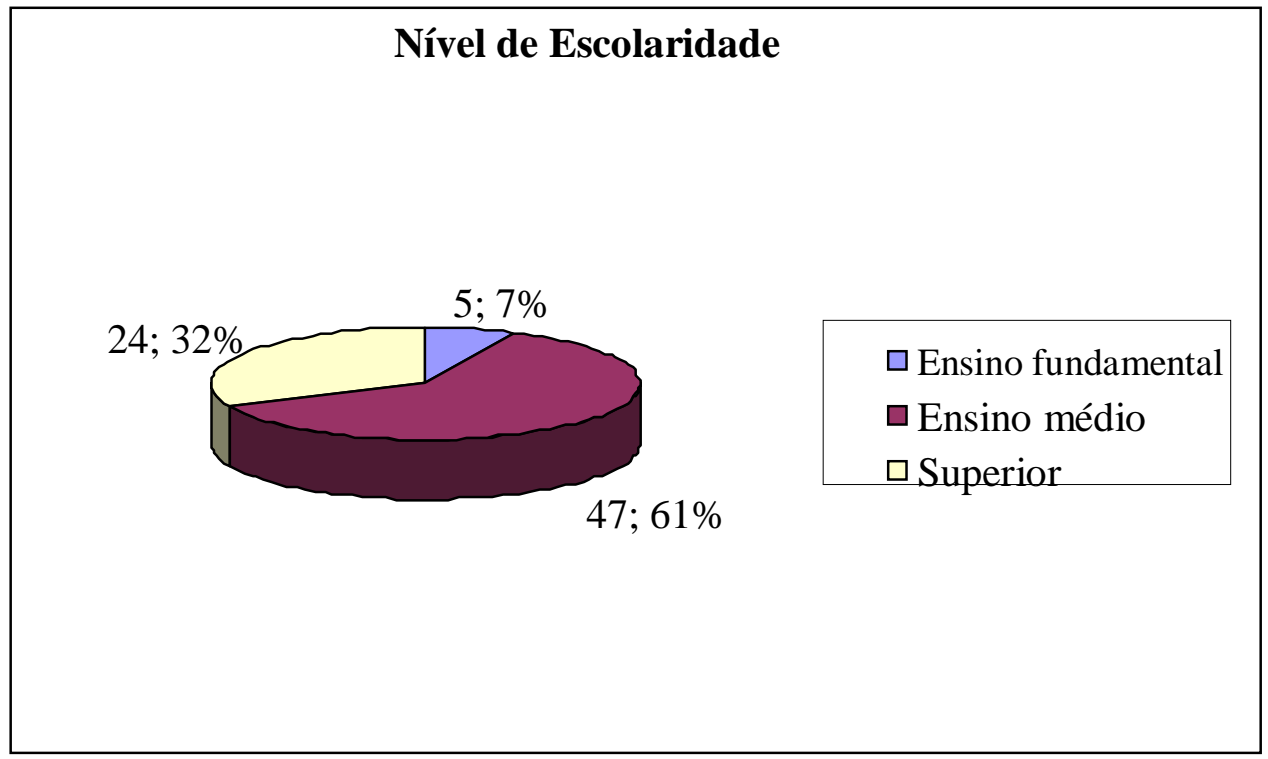

Figura 3 - Nível de escolaridade.

\section{Faixa etária dos funcionários}

\section{Faixa etária}

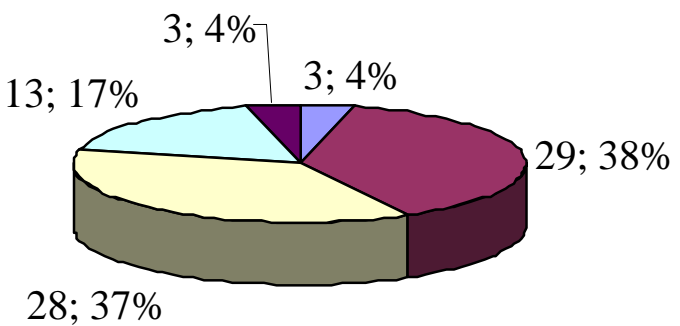

$\square 20$ a 30 anos

$\square 31$ a 40 anos

$\square 41$ a 50 anos

$\square 51$ a 60 anos

$\square$ acima de 60 anos

Figura 4 - Faixa etária.

\section{CONCLUSÃO}

Acerca dos resultados obtidos junto ao total de funcionários pesquisados evidenciam que existem conhecimentos satisfatórios sobre o programa de implantação do ISO 9000 na empresa em que atuam, e que receberam treinamento para se adequarem às novas regras do programa para aplicação na empresa. Muito embora, a maioria não se lembra exatamente do ano de implantação do ISO 9000 na sua empresa - fato menos relevante, o que importa é que a empresa já implantou e oferece oportunidades de sugestões para ampliação e melhorias no 
funcionamento do programa. Seus funcionários, além de terem recebido treinamento específico sobre o programa, também apresentam boa conscientização e perceberam excelentes mudanças de comportamento na empresa, além de se adaptaram sem maiores dificuldades ao programa do ISO 9000.

\section{REFERÊNCIAS}

BERGAMO FILHO, V. ISO 9000 em serviços: um passo para a qualidade total. São Paulo: Makron Books, 1999.

BONFIM, I. M. Crenças e valores dos auxiliares e técnicos de enfermagem frente a implantação do sistema de gestão da qualidade: ISO 9001:2000 no hospital do câncer de São Paulo. 2006. Disponível em: 〈http://www.teses.usp.br/>. Acesso em: 10 maio. 2010.

CAMPOS, V. F. TQC - Controle da qualidade total (no estilo japonês). 8. ed. Nova Lima: INDG, 2004.

CARPINETTI, L. C. R. et al. Gestão da qualidade ISO 9001: 2000 princípios e requisitos. São Paulo: Atlas, 2007.

CHIAVENATO, I. Administração nos novos tempos. 2. ed. Rio de Janeiro: Campus, 1999.

CHIAVENATO, I. Recursos humanos: edição compacta. São Paulo: Atlas, 2002.

DELGADO, J. Sensibilização para a importância da Qualidade no mercado actual. Disponível em: <http://www.ipv.pt/millenium/arq8_2.htm>. Acesso em: 10 maio. 2010.

MARSHAL JUNIOR, I. et al. Gestão da qualidade. 8. ed. Rio de Janeiro: FGV, 2006.

MELLO, C. H. P. et al. Sistema de gestão da qualidade para operações de produção e serviços.São Paulo: Atlas, 2007.

OLIVEIRA, K. C. G. et al. Percepção dos funcionários de uma industria do ramo de limpeza sobre o programa 5S. Nucleos - Revista Científica da fundação educacional de Ituverava, Ituverava, V. 4, n. 1-2, p. 223-235, set., 2007.

SGQ Consultoria e Treinamento S/C Ltda. Algumas perguntas frequentes sobre ISO 9000. Disponível em: < http://www.iso9000.com.br/basicas.htm >. Acesso em: 04 abr. 2009.

VALLS, V. M. O enfoque por processos da NBR ISO 9001 e sua aplicação nos serviços de informação. Ci. Inf., Brasília, v.33, n.22, p.172-178, maio/ago. 2004

YIN, R. K. Estudo de caso planejamento e métodos. 3 ed. Porto Alegre: Bookman, 2005. 


\section{ANEXO}

\section{ANEXO A - Questionário.}

Pesquisa de Percepção dos Funcionários Sobre a Implantação da ISO 9000.

Este Questionário tem como objetivo avaliar o conhecimento dos funcionários da empresa em relação à implantação da ISO 9000. Trata-se de uma Pesquisa Acadêmica, sendo preservado o nome de todos os respondentes de forma a não serem identificados.

1) A quanto tempo você trabalha na empresa, que cargo você ocupa?

( ) 1 ano ( ) 5 anos ( ) 10 anos ( ) 15 anos ( ) mais de 15 anos

Cargo:

2) Você sabe quando foi implantado o programa ISO 9000 na Empresa?
( ) $\operatorname{Sim}$
Quando
( ) Não

3) Você tem conhecimento sobre o programa ISO 9000 na Empresa?

( ) Sim ( ) Não ( ) Pouco ( ) Muito pouco ( ) Nunca ouvi falar

4) Você já participou de algum treinamento sobre ISO 9000 ?
( ) $\operatorname{Sim}$
( ) Não

5) Houve conscientização sobre como você deveria executar suas tarefas após a implantação da ISO 9000?
( ) $\operatorname{Sim}$
( ) Não

6) Você notou algum dos benefícios abaixo após a implantação do programa ISO 9000?

( ) Redução de desperdício

( ) Limpeza e organização

( ) Melhor relacionamento com a empresa

( ) Melhora na qualidade de vida no trabalho

( ) Maior responsabilidade

( ) Mais participação na execução ou tomadas de decisão

( ) Mais segurança

( ) Mais disciplina

( ) Melhor planejamento

( ) Melhoria no relacionamento entre os funcionários

7) Você sentiu dificuldade para adaptar ao programa?
( ) Sim
( ) Não

8) A empresa oferece meio de comunicação para você opinar ou sugerir melhorias no desempenho e funcionamento do programa?
( ) Sim
( ) Não

9) Qual seu nível de escolaridade?

( ) Ensino fundamental ( ) Ensino Médio ( ) Superior

10) Qual sua faixa etária?

( ) 20 a 30 ( )31 a 40 ( )41 a50 ( ) 51 a 60 ( ) 61 ou mais 